\title{
Coincidental aneurysms with tumours of pituitary origin
}

\author{
J A N J K UBOW S I A N D B R I N K E N D A L L \\ From the Gough Cooper Department of Neurological Surgery, Lysholm Radiological Department, \\ The National Hospital for Nervous Diseases, Queen Square, and the Neurosurgical and Radiological \\ Departments, The Middlesex Hospital, London
}

SUMMARY Angiographic studies on 150 pituitary adenomas and 33 craniopharyngiomas presenting for surgìcal treatment are reviewed. Eleven incidental silent aneurysms (four arising from the intracavernous and four from the supraclinoid carotid artery, and three from the anterior cerebral artery complex) are shown. Intracavernous aneurysms were also present in two acromegalic patients who had been treated previously with yttrium implantation. Although encasement of vessels by these tumours is unusual, the relevance of vascular abnormalities to surgical treatment is sufficient to justify routine magnification angiography.

The occurrence of "silent" intracranial aneurysms is well documented. Housepian and Pool (1958), in a detailed study of the cerebral arteries in 5762 necropsy cases collected between 1914 and 1956, found $32(0.56 \%)$ with aneurysms which had remained clinically silent. Du Boulay (1965) analysed carotid angiograms performed for tumour and vascular disease in 2595 cases and found silent aneurysms in $0.27 \%$. However, only $27 \%$ of the angiograms were bilateral, and the vertebrobasilar circulation was not outlined. Allowing for incomplete angiography, the incidence in the two studies is comparable.

Silent intracranial aneurysms located distant from the lesion to be treated have little relevance to surgical management of most patients. However, aneurysms of the major arteries adjacent to pituitary and suprasellar tumours are an additional hazard to surgical treatment. Previous knowledge of the presence and anatomy of such aneurysms is important during separation of the tumour capsule from the major vessels, or removal of an intracavernous extension of a tumour lying close to the carotid artery.

Giant aneurysms in the parasellar region presenting clinically as pituitary tumours are well

Address for reprint requests: Mr J. Jakubowski, Department of Neurosurgical Studies, The National Hospital, Queen Square, London WC1N 3BG.

Accepted 26 May 1978 recognised (Mitchell, 1889; Cushing, 1912; Jeffer-웅 그 son, 1937; White and Ballantine, 1961; Raymondọ and Tew, 1978) but silent aneurysms associated $\stackrel{\mathbb{Q}}{\stackrel{\mathbb{Q}}{2}}$ with symptomatic pituitary and suprasellar tumourso have not received so much attention. Two cases are referred to by Hankinson and Banna (1976), and they, and also Ambrose (1973), consider that one important reason for routine angiography on these tumours is to show incidental aneurysms: individual cases are described by Cushing (1912), Love (1963), Lippman et al. (1971) and von Alphen (1975), and illustrated by Gado and Bull (1971).

In general, the tumours are diagnosed clinically, confirmed by plain skull radiographs and their intracranial extension is assessed by pneumoencephalography. More recently, computed tomograms with coronal and axial sections have given considerable information on the extent and composition of these lesions, but many surgeons still prefer pneumoencephalograms to assess the relationship of the optic chiasm and nerves before a transcranial approach. In many neurosurgical units angiography is not performed unless the nature of the lesion is uncertain, especially if giant aneurysm or meningioma is suspected. The necessity of the procedure to show the precise relationships of vessels to masses in the pituitary region is debatable, but the use of magnification angiography for this purpose has revealed unsuspected vascular abnormalities with sufficient frequency to merit discussion. 


\section{Patients and methods}

We reviewed all proven cases of pituitary adenoma and craniopharyngioma presenting to the Department of Neurosurgical Studies at The National Hospital for Nervous Diseases between 1968 and 1978 and to the Middlesex Hospital between 1975 and 1978, in which angiograms were available.

The clinical features, tumour size, and angiographic abnormalities, including the presence and distribution of aneurysms, and the findings and results of surgery were noted.

\section{Results}

There were 183 cases -150 pituitary adenomas and 33 craniopharyngiomas. The histological diagnosis, age and sex distribution, and percentage of aneurysms are shown in Table 1 , and general angiographic findings in Table 2 . The cases referred for surgery in The National Hospital all had visual failure, caused by a moderate or large suprasellar extension. Many Middlesex Hospital patients presented with endocrine problems alone, but angiography was not performed in patients selected for a trans-sphenoid hypophysectomy, which included all cases with a tumour confined to the sella turcica or with only minor suprasellar extension. Nearly all the angiograms were performed to show vascular anatomy adjacent to a moderate or large suprasellar extension. Occasionally there was clinical doubt about the type of tumour, and angiography was carried out to elucidate. In one hypertensive acromegalic (case 2), a pneumoencephalogram showed only $5 \mathrm{~mm}$ suprasellar extension of the tumour, but it revealed a small mass suggesting an aneurysm (Fig. 1). An angiogram was performed specifically to confirm this and to exclude other aneurysms. In another acromegalic patient (case 12) who had been previously treated with yttrium implants, pain over the left eye was a prominent symptom, and raised the possibility of intracavernous aneurysm which was confirmed by angiography. Only one other patient had been treated previously, and in no other case were there any symptoms specifically suggestive of aneurysm.

The relevant features of the 11 cases with incidental aneurysms are set out in Table 3, and the distribution of aneurysms is shown in Fig. 2. Their clinical presentation was similar to that of the patients without aneurysms. Only one patient (case 2) was hypertensive. In six cases the aneurysm was well seen at surgery, and the angiographic data were considered significant to the safety of the procedure, but only one aneurysm (case 10) was treated. In the other patients, knowledge of the aneurysm was taken into account in surgical planning.

Two patients suffering from active acromegaly despite previous yttrium implants had aneurysmal dilatation of the cavernous segment of one carotid artery (Fig. 3). These aneurysms were considered more likely to be caused by the implant surgery rather than spontaneous, and are, therefore, not included in Table 3.

\section{Discussion}

The value of cerebral angiography combined with plain radiographs in the aetiological diagnosis of suprasellar tumours is universally accepted.

Table 1 Statistical analysis of presented cases

\begin{tabular}{|c|c|c|c|c|c|}
\hline & \multirow[t]{2}{*}{ Number } & \multirow{2}{*}{$\begin{array}{l}\text { Mean age }(S D) \\
(y r)\end{array}$} & \multicolumn{2}{|c|}{ Sex } & \multirow[t]{2}{*}{ Aneurysm } \\
\hline & & & $F$ & $\boldsymbol{M}$ & \\
\hline Chromophobe adenoma & 117 & $48.5(10.3)$ & 50 & 67 & $\begin{array}{r}6(5.1 \%) \leftarrow------\frac{1}{1}^{* *} \\
\quad P<0.005\end{array}$ \\
\hline $\begin{array}{l}\text { Eosinophilic or mixed adenoma } \\
\text { Basophilic adenoma } \\
\text { Craniopharyngioma }\end{array}$ & $\begin{array}{r}29 \\
4 \\
33\end{array}$ & $\begin{array}{lr}46.7 & (11.4) \\
45 & (8.6) \\
43 & (15.1)\end{array}$ & $\begin{array}{r}13 \\
3 \\
13\end{array}$ & $\begin{array}{r}16 \\
1 \\
10\end{array}$ & $\begin{array}{l}4(13.8 \%)+2 *=6(20.7 \%) \leftarrow- \\
\frac{1}{1}\end{array}$ \\
\hline
\end{tabular}

*Associated with previous yttrium implantation.

** $\chi^{2}$ test.

Table 2 General angiographic findings

\begin{tabular}{lccc}
\hline Vessels & Displaced & Narrowed & Occluded \\
\hline Intracavernous and/or supraclinoid carotid & $148(81 \%)$ & $10(5.4 \%)$ & 1 \\
Anterior cerebral & $128(70.3 \%)$ & $3(1.6 \%)$ & - \\
Middle cerebral & $5(2.7 \%)$ & - & - \\
\hline
\end{tabular}

*Two associated with previous yttrium implantation. 
Table 3 Clinical and radiological features and operative findings of cases presented

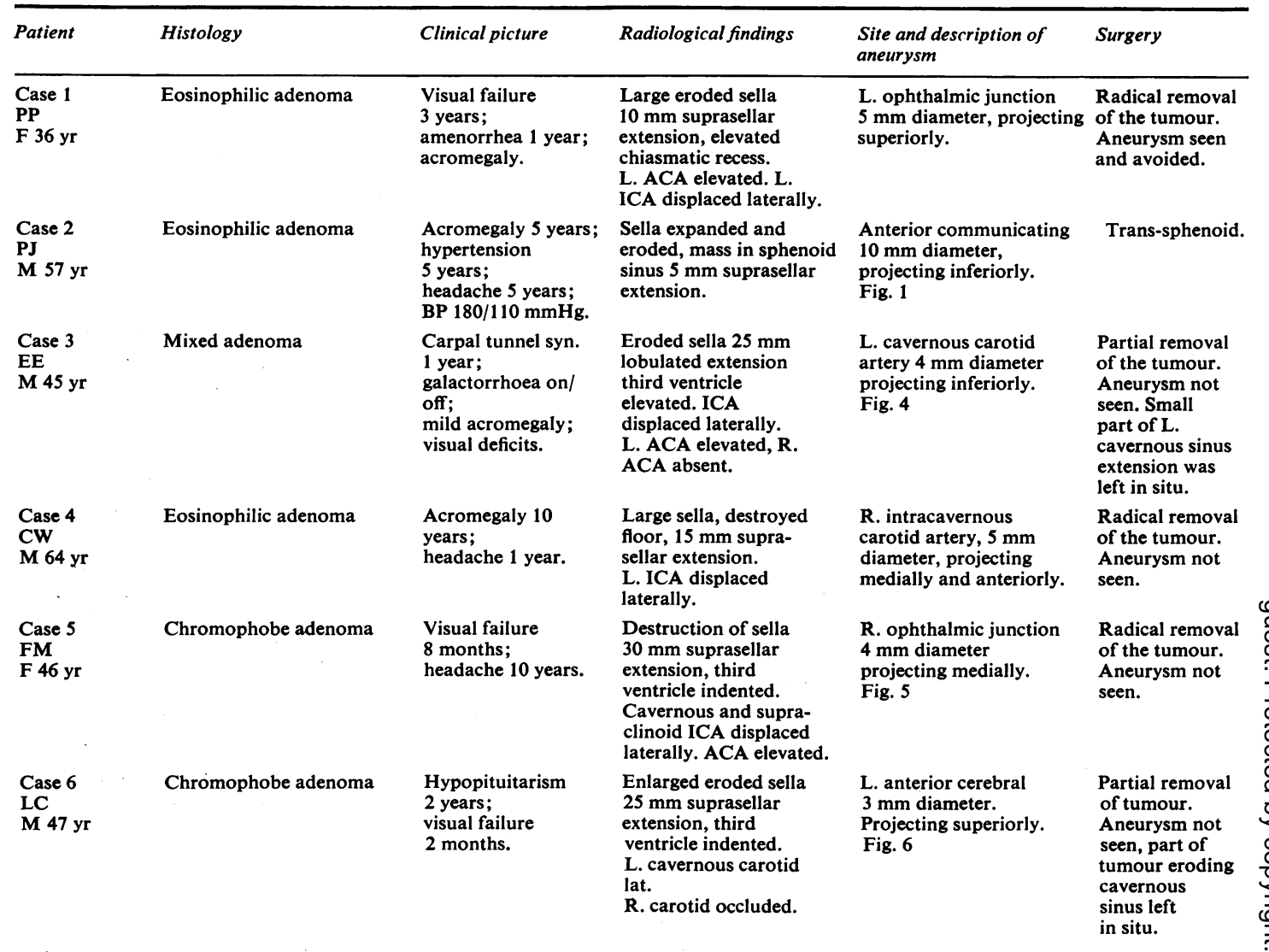

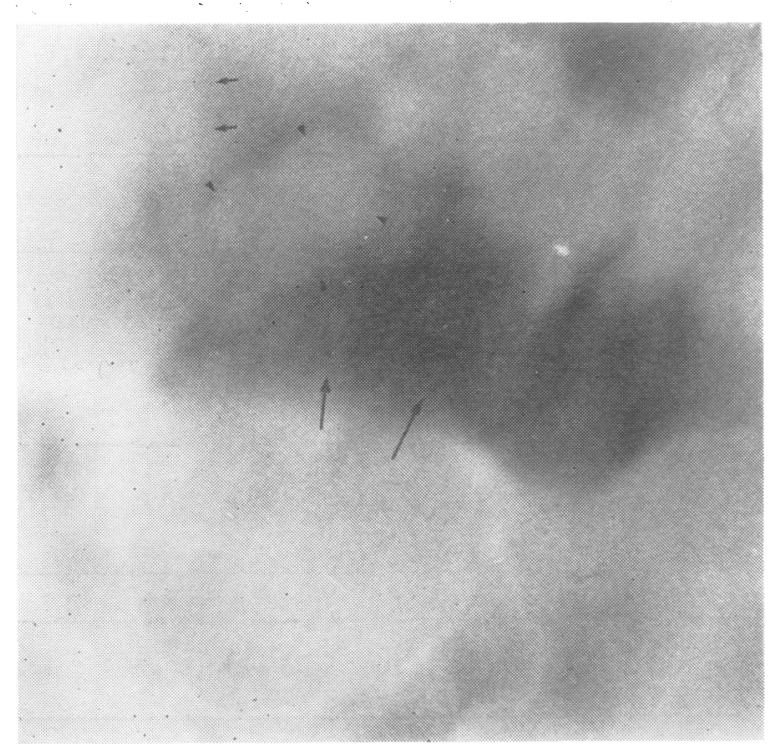

Fig. 1 Case 2. Pneumoencephalogram: erect lateral tomogram. Slight suprasellar extension of pituitary tumour (long arrows). Slightly lobulated anterior communicating aneurysm (arrow heads). Anterior cerebral arteries indicated by short arrows. 
Table 3 Clinical and radiological features and operative findings of cases presented (continued)

\begin{tabular}{|c|c|c|c|c|c|}
\hline Patient & Histology & Clinical picture & Radiological findings & $\begin{array}{l}\text { Site and description of } \\
\text { aneurysm }\end{array}$ & Surgery \\
\hline $\begin{array}{l}\text { Case } 7 \\
\text { EH } \\
\text { M } 53 \text { yr }\end{array}$ & Chromophobe adenoma & $\begin{array}{l}\text { Visual failure } \\
18 \text { months; } \\
\text { hypopituitary } \\
\text { syndrome. }\end{array}$ & $\begin{array}{l}\text { Large eroded sella } \\
25 \mathrm{~mm} \text { suprasellar } \\
\text { extension. Anterior part } \\
\text { of third ventricle } \\
\text { indented ACA } \\
\text { elevated (L. hypoplastic). } \\
\text { ICA displaced } \\
\text { laterally. }\end{array}$ & $\begin{array}{l}\text { R. distal carotid } \\
\text { artery } 8 \mathrm{~mm} \text { diameter } \\
\text { projecting superiorly } \\
\text { and anteriorly. } \\
\text { Fig. } 7\end{array}$ & $\begin{array}{l}\text { Partial removal } \\
\text { of the tumour. } \\
\text { Aneurysm seen, } \\
\text { capsule } \\
\text { attached to } \\
\text { aneurysm left } \\
\text { in situ. }\end{array}$ \\
\hline $\begin{array}{l}\text { Case } 8 \\
\text { EL } \\
\text { M } 56 \text { yr }\end{array}$ & Chromophobe adenoma & $\begin{array}{l}\text { Hypopituitarism } \\
11 \text { years; } \\
\text { visual failure } \\
1 \text { year. }\end{array}$ & $\begin{array}{l}\text { Sella expanded. } 20 \mathrm{~mm} \\
\text { suprasellar extension. } \\
\text { Cavernous } 1 C A \\
\text { displaced laterally } \\
\text { ACA elevated. }\end{array}$ & $\begin{array}{l}\text { R. intracavernous } 3 \mathrm{~mm} \\
\text { diameter, projecting } \\
\text { laterally. }\end{array}$ & $\begin{array}{l}\text { Radical removal } \\
\text { of the tumour. } \\
\text { Aneurysm not. } \\
\text { seen. }\end{array}$ \\
\hline $\begin{array}{l}\text { Case } 9 \\
\text { CD } \\
\text { F } 57 \text { yr }\end{array}$ & Chromophobe adenoma & $\begin{array}{l}\text { Visual failure } \\
2 \text { years; } \\
\text { hypopituitarism } \\
3 \text { months. }\end{array}$ & $\begin{array}{l}\text { Large expanded sella } \\
10 \mathrm{~mm} \text { posterior } \\
\text { suprasellar extension } \\
\text { post-fixed chiasma. } \\
\text { R. cavernous ICA } \\
\text { displaced laterally. } \\
\text { ACA elevated. }\end{array}$ & $\begin{array}{l}\text { R. carotid artery } \\
\text { origin of posterior } \\
\text { communicating artery } \\
4 \mathrm{~mm} \text { diameter } \\
\text { projecting inferiorly. }\end{array}$ & $\begin{array}{l}\text { Radical removal } \\
\text { of the tumour. } \\
\text { Aneurysm seen in } \\
\text { in contact with } \\
\text { tumour. Small } \\
\text { piece of capsule } \\
\text { attached to the } \\
\text { aneurysm was } \\
\text { left in situ. }\end{array}$ \\
\hline $\begin{array}{l}\text { Case } 10 \\
\text { WL } \\
\text { F } 62 \text { yr }\end{array}$ & Chromophobe adenoma & $\begin{array}{l}\text { Visual failure } \\
18 \text { months; } \\
\text { headache } 18 \\
\text { months; } \\
\text { hypopituitarism. }\end{array}$ & $\begin{array}{l}\text { Enlarged eroded sella } \\
10 \text { mm suprasellar } \\
\text { extension, lobulated. } \\
\text { Chiasmatic recess } \\
\text { elevated. Aneurysmal } \\
\text { mass seen. ACA } \\
\text { elevated. ICA displaced } \\
\text { laterally. }\end{array}$ & $\begin{array}{l}\text { R. anterior cerebral } \\
\text { artery } 12 \mathrm{~mm} \text { diameter, } \\
\text { multilocular projecting } \\
\text { posteriorly perforating } \\
\text { arteries close to neck. } \\
\text { Fig. } 8\end{array}$ & $\begin{array}{l}\text { Partial removal } \\
\text { of tumour. } \\
\text { Aneurysm seen in } \\
\text { contact with } \\
\text { tumour. Proximal } \\
\text { R. ACA clipped. }\end{array}$ \\
\hline $\begin{array}{l}\text { Case } 11 \\
\text { JS } \\
\text { M } 38 \mathrm{yr}\end{array}$ & Craniopharyngioma & $\begin{array}{l}\text { Hypopituitarism } \\
8 \text { years; } \\
\text { visual failure } \\
6 \text { months. }\end{array}$ & $\begin{array}{l}\text { Large eroded sella } \\
30 \mathrm{~mm} \text { suprasellar } \\
\text { extension, third } \\
\text { ventricle indented. } \\
\text { Cavernous ICA displaced } \\
\text { laterally. ACA elevated. }\end{array}$ & $\begin{array}{l}\text { R. intracavernous } \\
\text { carotid artery, } 7 \mathrm{~mm} \\
\text { diameter projecting } \\
\text { medially. } \\
\text { Fig. } 9\end{array}$ & $\begin{array}{l}\text { Partial removal } \\
\text { of the tumour. } \\
\text { Aneurysm not } \\
\text { seen. }\end{array}$ \\
\hline
\end{tabular}

Once a specific diagnosis has been established, the degree of intracranial extension and the relationship of neural structures can generally be determined more precisely by pneumoencephalography and computed tomography than by angiography, though in our selected series only $5.5 \%$ of the angiograms failed to show displacement of vessels caused by the tumour extension. It is rare for arteries to be enclosed within the tumour, and vessel displacement can usually be predicted from the extent of a mass shown on the other studies. In only one case in this whole series was an artery definitely narrowed, and in another occluded (Fig. 6) by encasement in the tumour. Considerable narrowing of the intracavernous carotid artery occurred in another patient, but it was probably part of more generalised atheroma. In the patient with carotid artery occlusion (case 6), collateral circulation through the meninges adjacent to the tumour was shown on the angiogram, and demonstration of these vessels may have a significant bearing on surgery in rare cases. It is the previous knowledge of incidental aneurysms which we consider to be of greater importance since this may allow planned modification of surgical approach to avoid damaging them or to include their treatment.

The high frequency of aneurysms demonstrated in this series may be due partly to angiographic technique. In $80 \%$ of the cases bilateral carotid angiography was performed, and in the other $20 \%$ good cross flow was obtained, usually with reflux
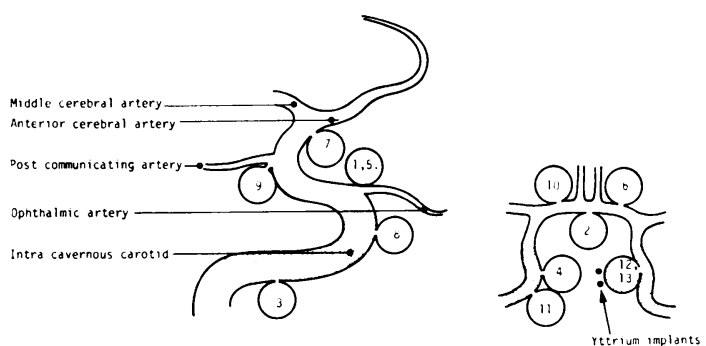

Fig. 2 Diagram indicating position of aneurysms. Numerals refer to case numbers (see text). 


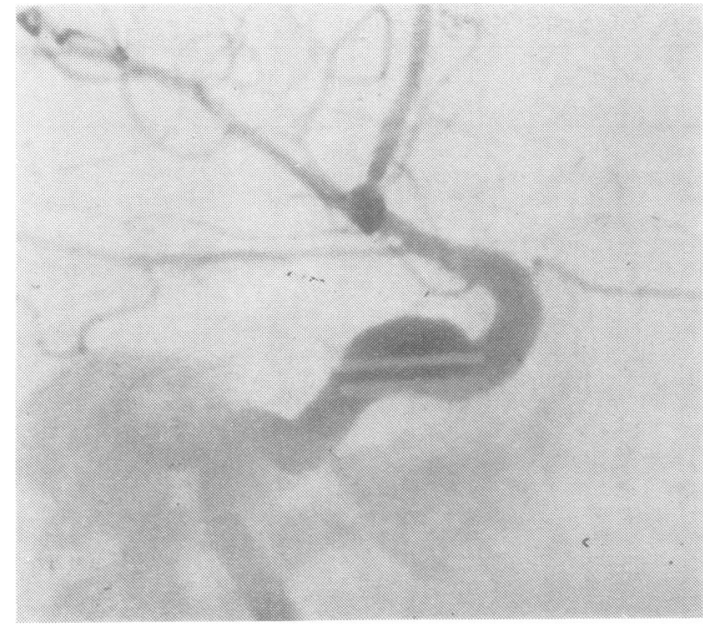

(a)

Fig. 3 Case 12. Left carotid angiogram subtraction prints: (a) lateral, (b) antero-posterior projection. The yttrium implants are visible in contact with medially projecting aneurysmal dilatation of cavernous segment of internal carotid artery.

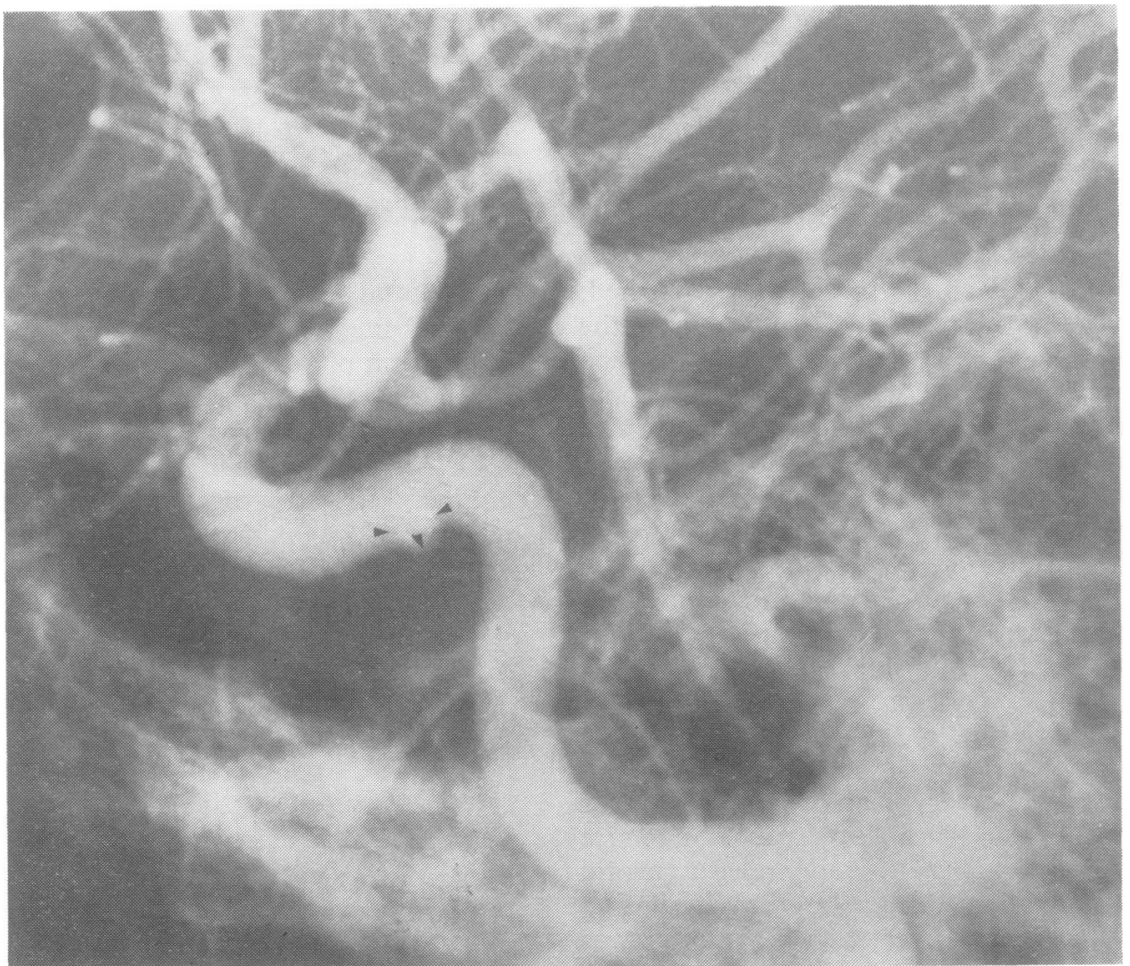

Fig. 4 Case 3. Left carotid angiogram, lateral projection. Intracavernous aneurysm (arrow heads) projecting inferiorly and slightly medially, partially superimposed on 


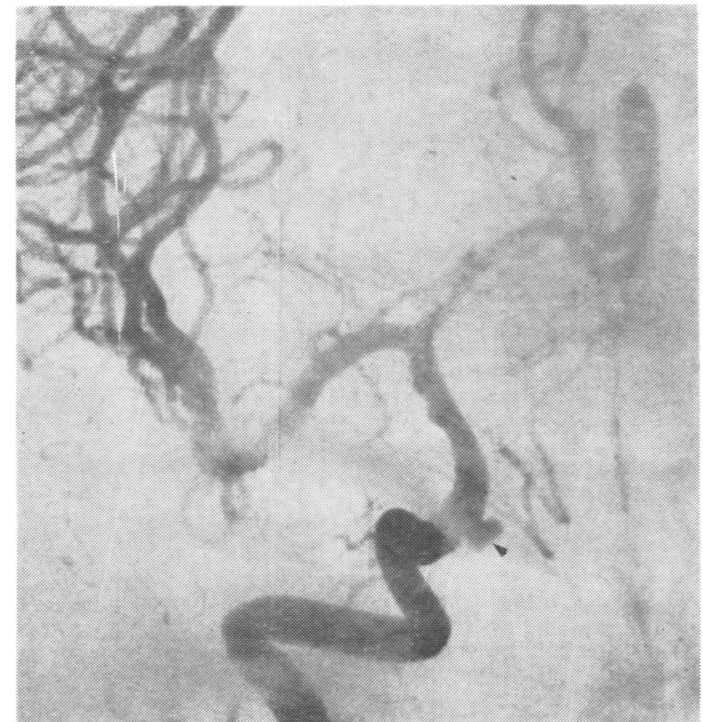

Fig. 5 Case 5. Right carotid angiogram, subtraction print antero-posterior projection. The intracavernous and supraclinoid segments of the internal carotid artery are displaced laterally. The anterior cerebral artery is elevated. There is an unilocular aneurysm projecting superiorly and medially from the supraclinoid carotid, at the origin of the ophthalmic artery.

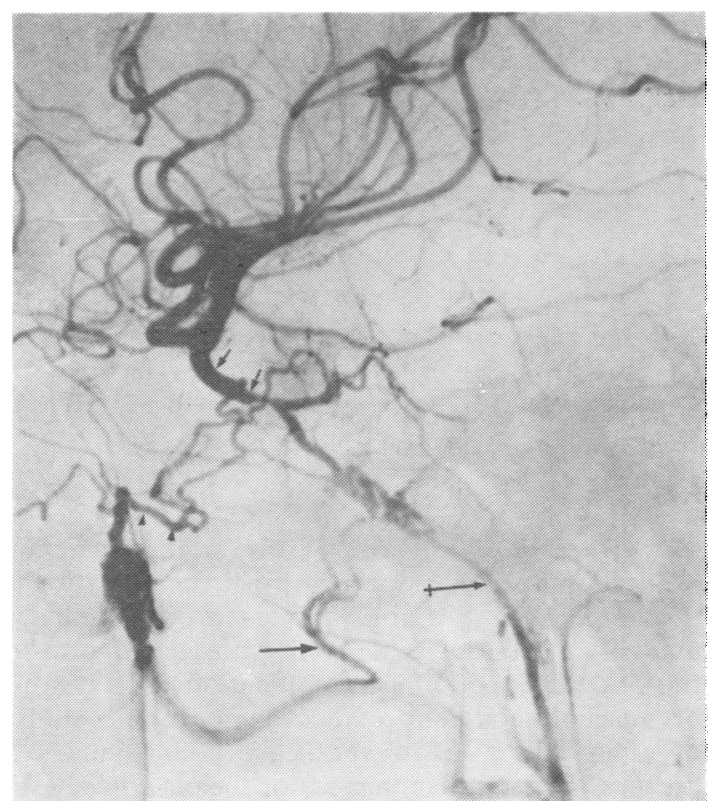

$6(a)$
Fig. 6 Case 6. Right common carotid angiogram subtraction print, lateral projection. (a) The internal carotid artery is occluded. There is filling of the cavernous carotid artery (short arrows) through meningeal branches of the ascending pharyngeal artery (crossed arrow), middle meningeal artery (long arrow) and artery of foramen rotundum (arrow heads). (b) Tumour blush is shown around the cavernous carotid artery. (c) Left carotid angiogram subtraction print, antero-posterior projection. The cavernous segment is displaced laterally. There is a small anterior cerebral aneurysm (arrow head).
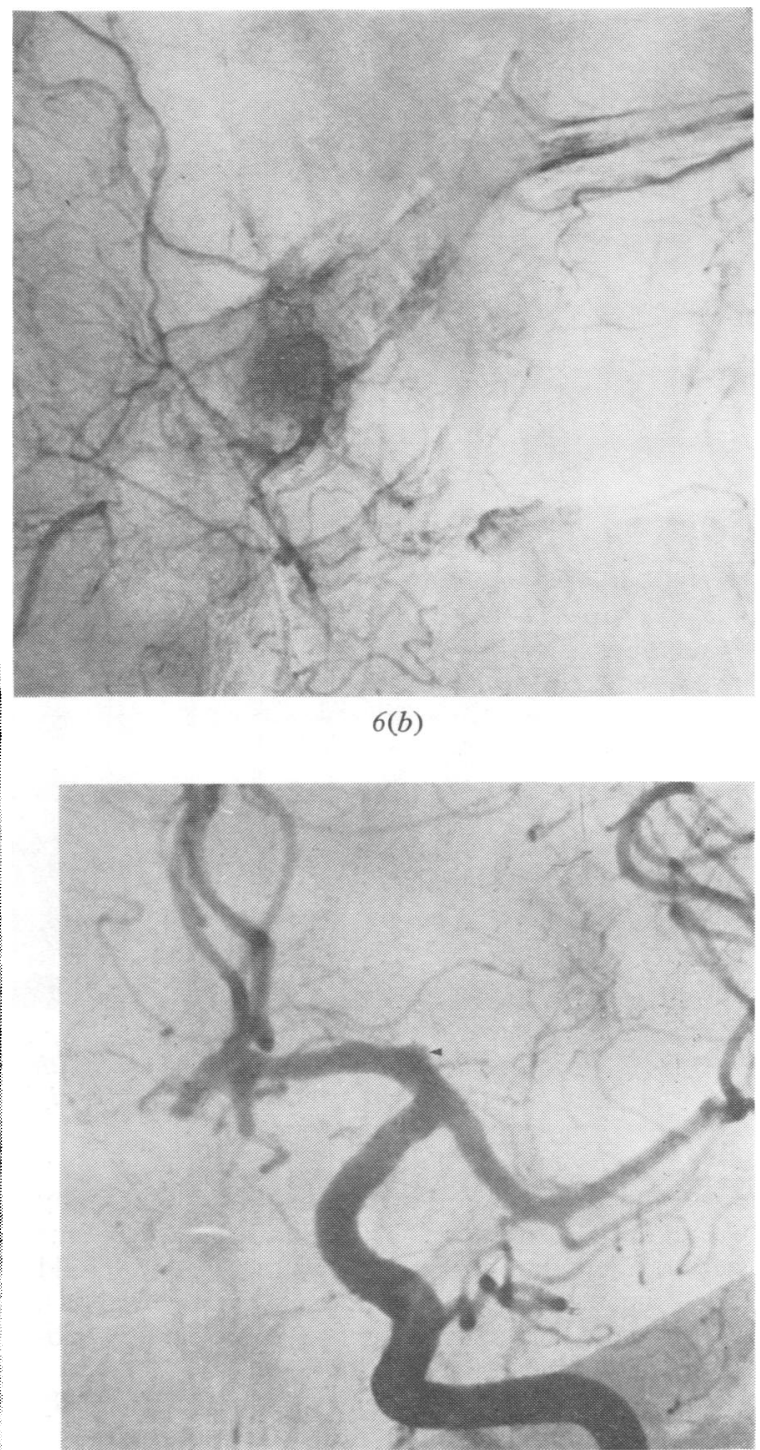

$6(c)$ 


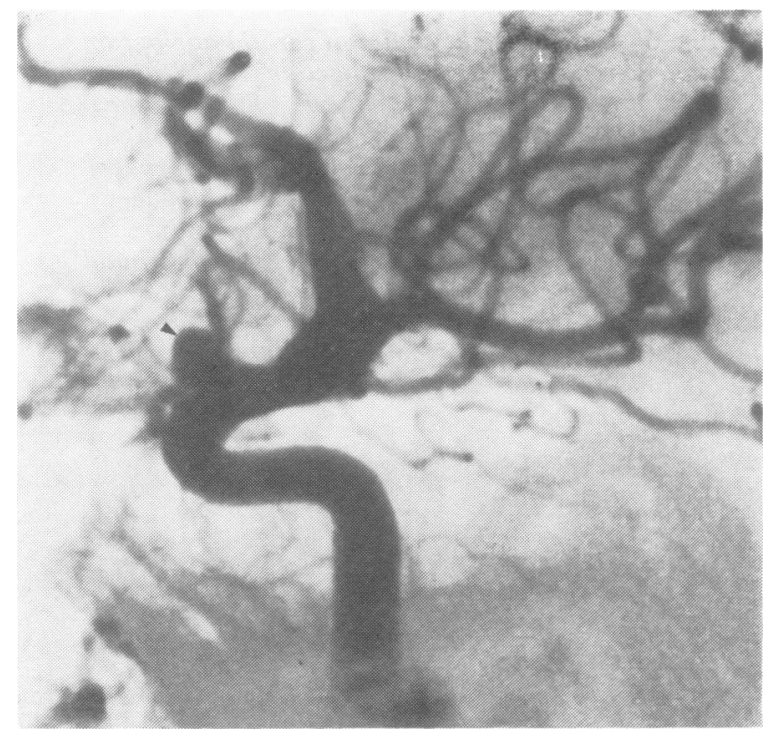

Fig. 7 Case 7. Right internal carotid angiogram subtraction print lateral projection. Distal carotid aneurysm projecting anteriorly and superiorly (arrow head).

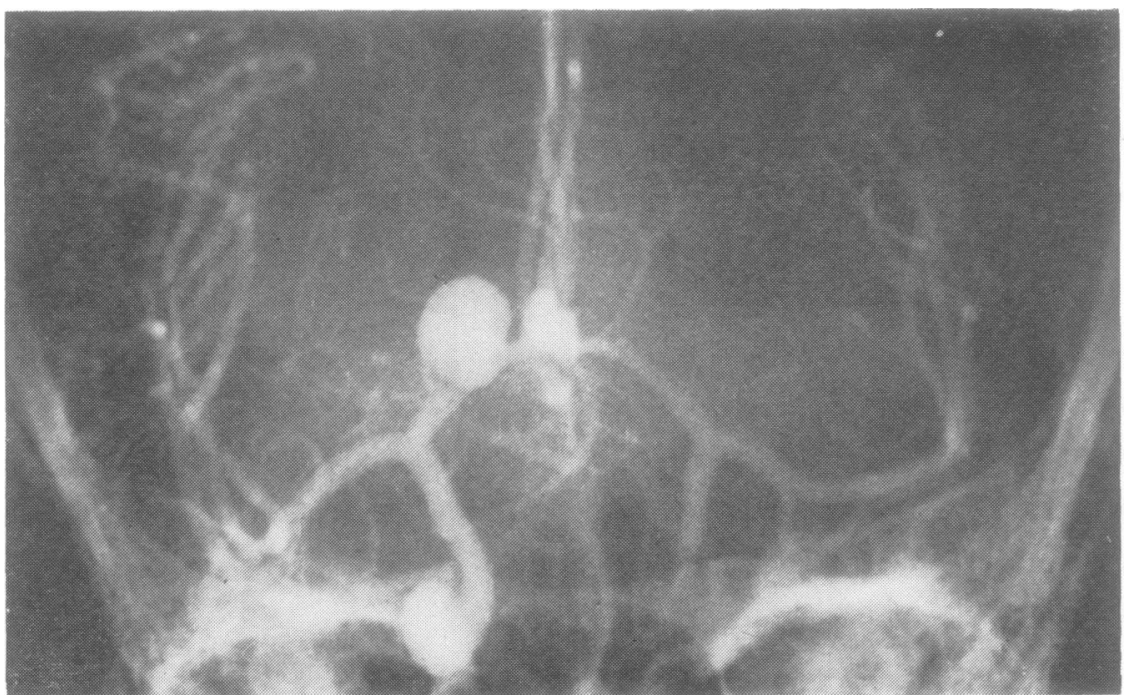

Fig. 8 Case 10. Right carotid angiogram antero-posterior projection with cross compression. Lateral displacement of both supraclinoid segments and elevation of anterior cerebral arteries. Multilocular right anterior cerebral aneurysm projecting superiorly and posteriorly.

down the contralateral artery, so that angiography was generally complete. Though all the aneurysms were larger than $3 \mathrm{~mm}$ in diameter and could have been shown by conventional methods, magnification was routine. Radiographic subtraction was performed as indicated.

Angiograms had not been performed previously in the two cases with aneurysms adjacent to yttrium implants, so that it is not possible to be sure whether these aneurysms were incidental, post-traumatic, or associated with the radiation in the immediate proximity. It is probable that a majority of these aneurysms were traumatic but the incidence of this complication is unknown because of lack of previous angiographic studies of these cases. However, cavernous sinus syndromes and fistulas have not been noted after pituitary implants so that progressive growth 


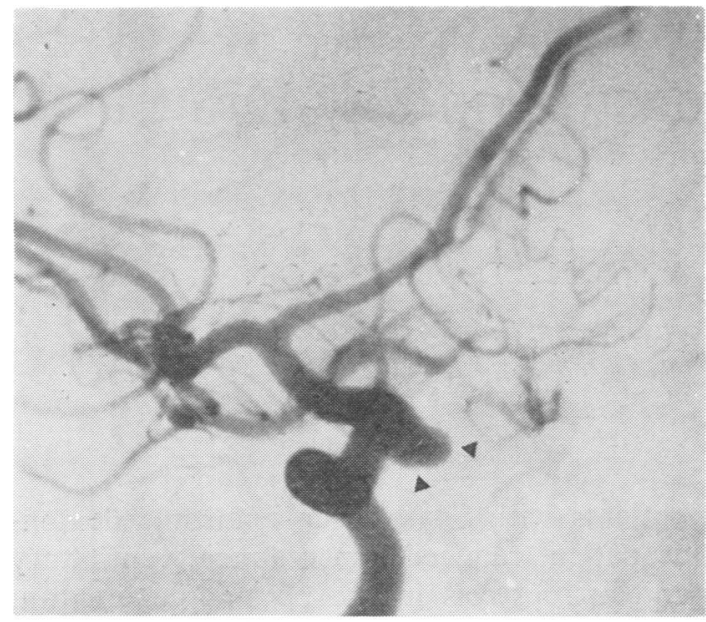

Fig. 9 Case 11. Right carotid angiogram, oblique projection, subtraction print. A wide-necked intracavernous aneurysm is shown projecting medially (arrow heads).

and rupture of any complicating aneurysms must be rare. The demonstration of two such aneurysms in our sample suggests that angiography should certainly be performed before implantation or subsequent surgery in the region of implants. The intracavernous segments of the carotid arteries may encroach up to the midline. Their anatomy should be determined before pituitary implantation.

The reason for the higher frequency of aneurysms in association with these tumours than that of incidental aneurysms previously recorded is unknown. There were no obvious clinical differences between these cases and the rest of our series, and, apart from case 2 previously mentioned, there was no evidence of diffuse vascular disease or hypertension. With the exception of the anterior communicating aneurysm in case 2, the aneurysms were all on vessels adjacent to the tumours. This suggests the possibility of a mechanical effect, perhaps associated with increased tension on or flow through small vessels supplying the tumour. There was, however, no obvious difference in the vascularity of the tumours with aneurysms and that of the rest of our cases.

A relationship between acromegaly and vascular disease is established, and the proportion of aneurysms was much greater in our cases with acromegaly. It may be that abnormal pituitary hormone levels, which were present in all our cases, affect the arterial walls and predispose to aneurysm formation.

We wish to thank Mr John Andrew, Consultant Neurosurgeon at The Middlesex Hospital, London, and Professor Lindsay Symon of The National Hospital, Queen Square and Maida Vale, for their helpful criticism of the paper.

\section{References}

Alphen, von H. A. M. (1975). Microsurgical frontotemporal approach to pituitary adenomas with extrasellar extension. Clinical Neurology and Neurosurgery, 78, 247-256.

Ambrose, J. (1973). Radiological diagnosis of pituitary tumours. In Pituitary Tumours, pp. 79-121. Edited by J. S. Jenkins. Butterworths: London.

Cushing, H. (1912). The Pituitary Body and its Disorders. Clinical states produced by disorders of the hypophysis cerebri. J. B. Lippincott: Philadelphia.

Du Boulay, G. H. (1965). Some observations on the natural history of intracranial aneurysms. British Journal of Radiology, 38, 721-757.

Gado, M., and Bull, J. W. D. (1971). The carotid angiogram in suprasellar masses. Neuroradiology, 2, 136-153.

Hankinson, J., and Banna, M. (1976). Pituitary and Parapituitary Tumours. W. B. Saunders: Eastbourne.

Housepian, E. M., and Pool, J. L. (1958). A systematic analysis of intracranial aneurysms from the autopsy file of the Presbyterian Hospital 1914-1956. Journal of Neuropathology and Experimental Neurology, 17, 409-423.

Jefferson, G. (1937). Compression of the chiasma, optic nerves and optic tracts by intracranial aneurysms. Brain, 60, 444-497.

Lippman, H. H., Onotrio, B. M., and Baker, H. L. (1971). Intrasellar aneurysm and pituitary adenoma: report of a case. Proceedings of the Mayo Clinic, 46, 532-535.

Love, J. G. (1963). Association of carotid aneurysm with neoplasm compressing the optic chiasm. Proceedings of the Staff Meetings of the Mayo Clinic, 38, 156-161.

Mitchell, S. W. (1889). Aneurysm of an anomalous artery causing antero-posterior division of the chiasma of the optic nerves and producing bitemporal hemianopia. Journal of Nervous and Mental Disease, 14, 14-62.

Raymond, L. A., and Tew, J. (1978). Large suprasellar aneurysms imitating pituitary tumour. Journal of Neurology, Neurosurgery, and Psychiatry, 41, 83-87.

White, J. C., and Ballantine, H. (1961). Intrasellar aneurysms simulating hypophyseal tumors. Journal of Neurosurgery, 18, 34-50. 